\title{
Quality of Life in Children with Cerebral Palsy
}

\section{Ozlem Cinar Ozdemir and Sezen Tezcan}

Additional information is available at the end of the chapter

http://dx.doi.org/10.5772/67996

\begin{abstract}
Cerebral palsy is a complex and serious disease that can affect all age groups around the world. There is no prevalence differentiation between developed and developing countries. Preeclampsia, maternal trauma, low birth weight, gestational age, birth asphyxia, intrauterine infection, etc. can also be included in the list of risk factors. Functional limitations, self-care difficulties, behavioral problems, seizures, cognitive, sensory, social and emotional impairments and difficulties of daily life activities can affect health-related quality of life in children and adolescents with cerebral palsy. So, it is important to evaluate health-related quality of life in cerebral palsy. It is stated that there are many generic instruments to evaluate health-related quality of life. However, using specific instruments for cerebral palsy is more sensitive than generic instruments to evaluate effect of cerebral palsy in children's health-related quality of life. The aim of this chapter is to investigate health-related quality of life instruments in children and adolescents with cerebral palsy.
\end{abstract}

Keywords: cerebral palsy, health-related quality of life, quality of life, generic measures, condition-specific measures

\section{Introduction}

Cerebral palsy (CP), in its broadest definition issued by the "Surveillance of Cerebral Palsy in Europe"(SCPE), "is a group of permanent disorders in the development of movement and posture, causing activity limitations that are attributed to non-progressive disturbances that occurred in the developing fetal or infant brain." CP incidence is within the range of 1.5-2.5 per 1000 live births. In premature births and extreme low birth weights, this range elevates to 40-100 per 1000 live births [1]. 
Between the years 1980 and 2000, CP prevalence was within the range of 1.3-4.4 per 1000 live births, and there is no prevalence differentiation between developed and developing countries. Europe, North America, Australia, Hong Kong and Japan-based studies demonstrated that prevalence ratios were within the range of 1.3-3.6 per 1000 live births [2-5]. In China [6], Turkey [7] and India [8], on the other hand, these ratios varied between the ranges of 1.3 and 4.4 per 1000 live births [9].

Studies have ensured the following statistics, commonly reported in the United States:

- About 764,000 children and adults currently have CP.

- About 500,000 children under the age of 18 currently have CP.

- About two to three children out of every 1000 have cerebral palsy (the United States studies have yielded rates as low as 2.3 per 1000 children to as high as 3.6 per 1000 children).

- About 10,000 babies born each year will develop CP.

- Around 8000-10,000 babies and infants are diagnosed per year with CP.

- Around 1200-1500 preschool-aged children are diagnosed per year with CP [10].

\section{Risk factors and known causes of $\mathrm{CP}$}

Risk factors in CP have been classified as prenatal, perinatal and postnatal phases (Table 1). Prenatal maternal risk factors are associated with delayed onset of menstruation, irregular menstruation cycles, an extended menstrual cycle, and maternal drug use, which have all been associated with an increased ratio of $\mathrm{CP}$ risk. Among perinatal causes are preeclampsia, maternal

\begin{tabular}{lll}
\hline Prenatal & Perinatal & Postnatal \\
\hline Maternal disease in pregnancy & Length of labor & Neonatal seizures \\
Oligohydramnios & Membrane rupture & Respiratory distress syndrome \\
Polyhydramnios & Induction of labor & Hypoglycaemia \\
Perinatal infection & Augmentation & Jaundice \\
Pre-eclampsia & Meconium & Infections (meningitis, sepsis,malaria) \\
Placental abnormalities & Abnormal fetal presentation & \\
Small for gestational age & Mode of delivery & \\
Large for gestational age & Birth asphxia & \\
Placenta praevia & Sentinel events(cord prolapse, cord \\
& $\begin{array}{l}\text { around neck, specifically tight cord, } \\
\text { uterine rupture) }\end{array}$ & \\
Hemorrage & & \\
\hline
\end{tabular}

Table 1. Risk factors of CP. 
trauma, antepartum hemorrhage, Factor V Leiden mutation, gene for prothrombin, placental thrombose, neonatal stroke, autoimmune and coagulation disorders, and multiple pregnancies. Cephalopelvic disproportion, largeness or abnormal positioning of the fetus that are linked with the cord prolapse induced perinatal asphyxia; severe intrapartum hemorrhage; extended or traumatic labor experience, also extension of the second phase of labor; emergency caesarean section; early separation of placenta; abnormal fetal position; chorioamnionitis; meconium presence; tight nuchal cord are among the $\mathrm{CP}$ risk factors while delivering the baby [11]. Preterm birth, emboli and thrombose, intrauterine infection, genetic disorders, neonatal seizures, neonatal sepsis, and respiratory diseases are the other critical risk factors of developing CP [12, 13]. $\mathrm{CP}$ prevalence is strongly linked with gestational age and birth weight. Literature studies manifested that babies with an extra-low birth weight (below $1500 \mathrm{~g}$ ) are 20-80 times likely to develop $\mathrm{CP}$ when compared to babies with 2500 and higher grams of birth weight [14, 15].

Depending on the time brain damage occurred, it would be illuminating to classify causes for $\mathrm{CP}$ as prenatal, perinatal, postnatal (Table 2). Prenatal causes are congenital malformations, vascular incidences, and maternal infections detected during the first and second trimesters (rubella, cytomegalovirus, toxoplasma). Rarely experienced causes during prenatal period are metabolic diseases, maternal toxin intake and infrequent genetic syndromes. Perinatal causes are obstructed labor, and antepartum hemorrhage, neonatal ensefalopati that might be certain risk factors for triggering hypoxia of the fetus. Infection and injuries, cerebrovascular events, meningitis, septicemia and malaria can also be included in the list of postnatal causes [11].

\begin{tabular}{lll}
\hline Prenatal & Perinatal & Postnatal \\
\hline Congenital brain malformations & Obstructed labor & Infection \\
Vascular events & Antepartum hemorrhage & İnjuries \\
$\begin{array}{l}\text { Maternal infections } \\
\text { during the first and second } \\
\text { trimesters of pregnancy(rubella, } \\
\text { cytomegalovirus, }\end{array}$ & Cord prolapse & Apparent life-threatening events \\
$\begin{array}{l}\text { Metabolic disorders } \\
\text { Maternal ingestion of toxins }\end{array}$ & Neonatal encephalopathy & \\
& & Cerebrovascular accidents \\
Rare genetic syndromes & & Following surgery for congenital \\
& & malformations \\
& & Meningitis \\
\end{tabular}

Table 2. Known causes of CP.

\section{Classification of $\mathrm{CP}$}

\subsection{Classification on the basis of neurological findings}

1956-dated classification system issued by the American Cerebral Palsy Academy is still commonly utilized system of today: four motor types have been classified as spastic, dyskinetic, 
ataxic, and hypotonic (Figure 1) [16, 17]. Spastic type has been subcategorized as: spastic hemiplegia, spastic diplegia, spastic quadriplegia, and dyskinetic type has been subcategorized as: chorea, athetosis, ballismus, tremor, rigidity, dystonia [18]. Among children with $\mathrm{CP}$, the most prevalent type is spastic (58\% bilateral and 30\% unilateral), and the second most prevalent type is dyskinetic type (7\%). Ataxic type is common in a ratio of $4 \%$, and there are certain unclassifiable forms with a ratio of $1 \%[1,19]$.

Spastic CP: This is the most common form of CP [20]. It has been detected that $35 \%$ of spastic $\mathrm{CP}$ cases are hemiparetic, $28 \%$ are diparetic, and $37 \%$ are quadriparetic $[16,20]$. In some studies, hemiparetic, diparetic, quadriparetic terminologies are replaced with the terms unilateral and bilateral [21, 22].

Among children with spastic quadriplegia that integrates four extremities, the severity of influence is extremely high (Figure 2). Retardation in physical development, severe mental retardation, seeing, hearing, chewing, swallowing and speaking impairments, pseudobulbar palsy and accompanying orofacial impairments, unmanageable epileptic seizures are often frequently experienced among these children [23].

Spastic hemiplegia is a unilateral paresis in which upper extremity is much more impacted than lower extremity (Figure 3). Its prevalence in term infants is 56 and $17 \%$ in preterm infants [24]. In upper extremity grasp action of the thumb, wrist extension and supination are the most impacted functions, while in lower extremity, dorsiflexion and eversion are among the most impacted functions. Flexor tonus has risen in parallel with hemiparetic posture, elbow and wrist flexion, harvesting position of the knees and feet. Sense anomalies are frequent incidences in the affected extremities. Two-point discrimination and position sensation have also been deteriorated in these cases. Visual field defect, homonym hemianopsia, cranial nerve anomalies, and facial nerve palsy at most are likely to be observed [24].

In spastic diplegia, lower extremities are more severely impacted than upper extremities (Figure 4). Among mildly impacted children, in effect of increased tonus of the muscles surrounding the ankle, emerging impaired dorsiflexion may lead to walking on the balls of the

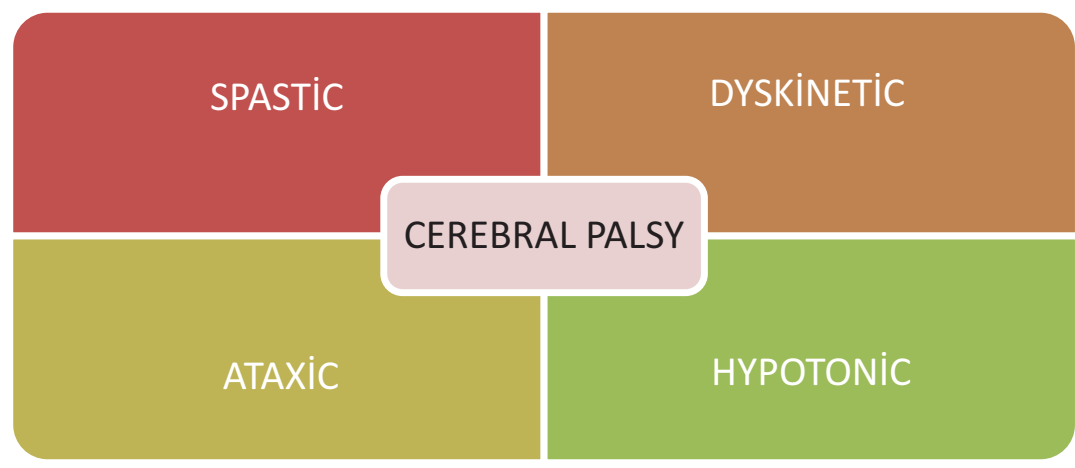

Figure 1. Classification on the basis of neurological findings. 


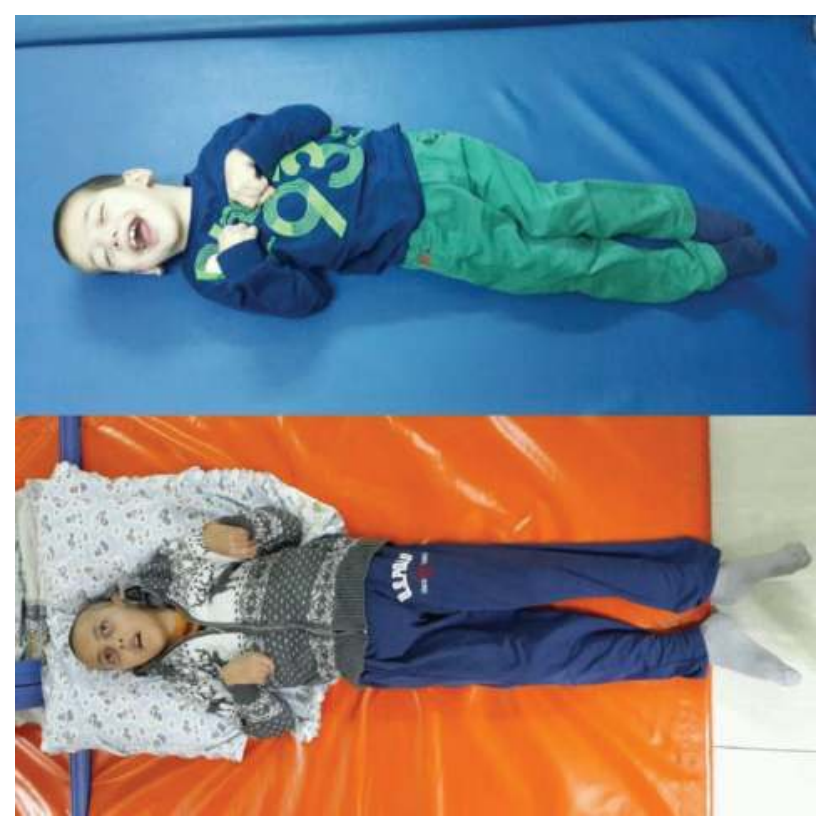

Figure 2. Spastic quadriplegia.

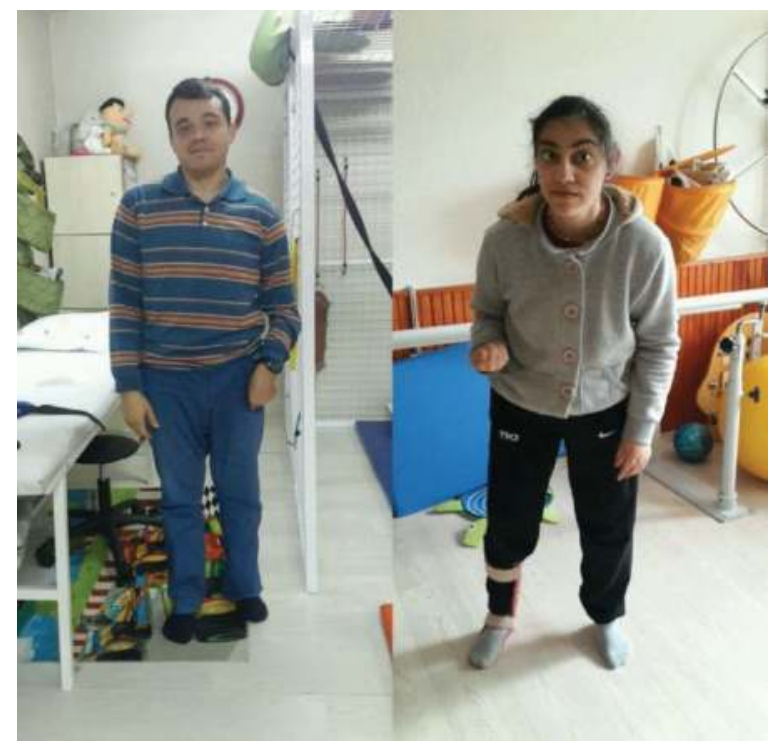

Figure 3. Spastic hemiplegia. 


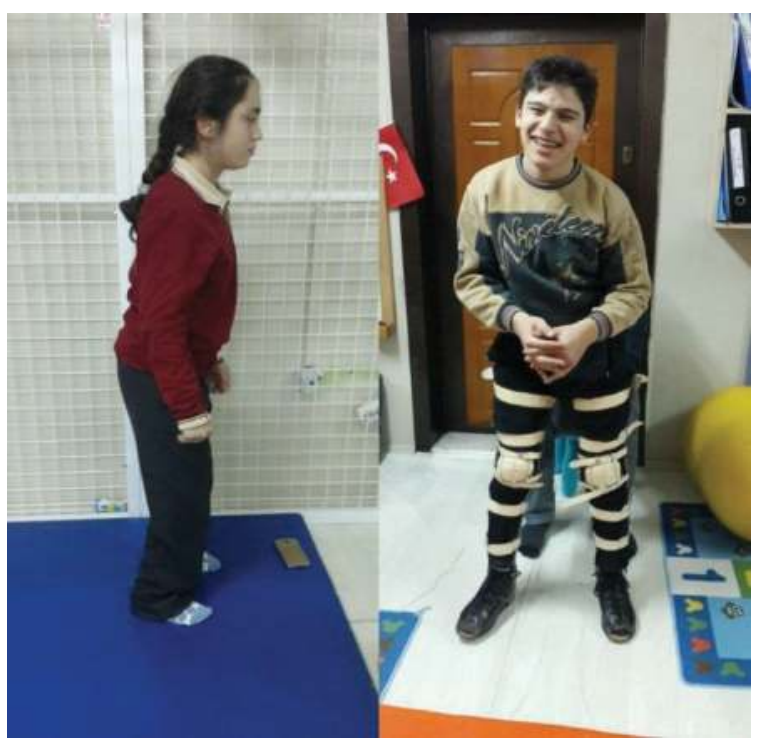

Figure 4. Spastic diplegia.

feet, while in severely affected cases, it is also common to see hip and knee flexion as well [24]. Spastic diplegia is basically triggered by prematurity and low birth weight [25]. When the child stands upright, rigidity in lower extremities is quite visible and due to adductor spasm, there is the scissoring of legs. Sense-perception impairments, epilepsy, mental retardation and strabismus are likely to be detected in such cases [25, 26].

Dyskinetic-type CP: Dyskinetic CP is characterized with unmanageable and unintended bodily movements, and dyskinetic-type $\mathrm{CP}$ includes subtypes such as chorea, athetosis, ballismus, tremor, rigidity, and dystonia [27].

Athetosis refers to unintended slow bodily movements such as convulsion. It is mostly common in major joints as major movements and in such movements problems such as timing, distance measuring or movement control are frequently problematic. Rigidity is less prevalent, and there is resistance against passive and active movement. Tremor is rhythmic and small actions mostly prevalent in minor joints. It is usually accompanied with athetosis or ataxia. Dystonia refers to slow, torsional movements that could either impact a single joint or the whole body. Ballismus is the least-prevalent movement disorder. They are random movements in a broad and speedy pattern and commonly observed in a single joint. Chorea includes irregular movements [28].

This type of $\mathrm{CP}$ is characterized with birth asphyxia. Severity of dystonic postures is likely to change with respect to body position, emotional state and sleep. On dyskinetic $\mathrm{CP}$, primitive reflexes are more accentuated and sustained for longer periods. These movement patterns diminish in sleep when tonus in impacted extremities is comparatively weaker. It is also common to see posture control and coordination anomalies [24]. 
Ataxic CP: Children with ataxic $\mathrm{CP}$, balance and coordination system are the most affected one. These children are able to walk only by keeping wide the support surface, and they have severe tremors adversely affecting performing well in daily activities that call for good motor functions [29]. It is common to see cerebellum damage at most [28]. In ataxic CP, the overall condition may be accompanied with spasticity, athetosis, nystagmus, speaking problems, mental retardation, and epilepsy [30].

Hypotonic CP: The basic negation among children with hypotonic-type CP is hypotonia in all muscles [28]. In the advanced levels spasticity, dyskinesia and ataxia in particular may develop in these children. In effect of hypotonia, there is growth retardation, abnormal tendon reflexes and absence of primitive reflexes (Figure 5) [23].

\subsection{Classification based on motor function}

In children with $\mathrm{CP}$, walking ability is strongly affected [31]. Gross Motor Function Classification System (GMFCS) is a classification system developed by Palisano et al. for children with chronic disability and based on the movements initiated by the child him/herself such as sitting, moving and acting. Since children's motor functions are subject to change with the range of age, for each level, functions have been categorized as below age 2; within the age range of $2-4$, within the age range of $4-6$, and within the age range of $6-12$. In the past, the system was only employed for children below age 12, and with its extended version, it can be used for the adolescents of age group 12-18 presently (Table 3) [32].

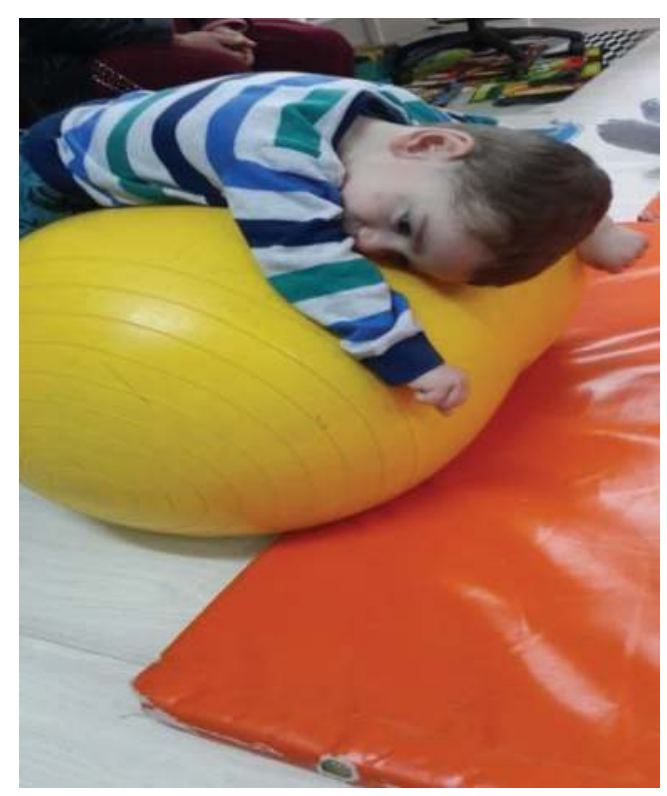

Figure 5. Hypotonic CP. 


\section{GMFCS}

\begin{tabular}{ll}
\hline Level I & Walks without limitations; limitations in more advanced gross motor skills \\
Level II & Walks with limitations; limitations walking outdoors and in the community \\
Level III & $\begin{array}{l}\text { Walks with adaptive equipment assistance; limitations walking outdoors and in } \\
\text { the community }\end{array}$ \\
Level IV & $\begin{array}{l}\text { Self-mobility with use of powered mobility assistance; children are transported } \\
\text { or use power mobility outdoors and in the community }\end{array}$ \\
Level V & Self-mobility is severely limited even with the use of assistive technology \\
\hline
\end{tabular}

Table 3. Gross Motor Classification System (GMFCS) [30].

Other classification systems employed among children with CP are Manual Ability Classification System (MACS) and Bimanual Fine Motor Function (BFMF) (Table 4) [33, 34]. MACS is a classification system that analyzes the way aged 4-18 children with CP use their hands while carrying objects in their daily activities. System does not measure maximum capacity of a child with

\begin{tabular}{ll}
\hline LEVEL I & $\begin{array}{l}\text { Mandles objects easily and successfully. At most } \\
\text { limitations in the ease of performing manual } \\
\text { tasks requiring speed and accuracy. However, } \\
\text { any limitations in manual abilities do not restrict } \\
\text { independence in daily activities. }\end{array}$ \\
LEVEL II & $\begin{array}{l}\text { Handles most objects, but with somewhat } \\
\text { reduced quality or speed of achievement. Certain } \\
\text { activities may be avoided or achieved with some } \\
\text { difficulty; alternative ways of performing might } \\
\text { be used, but manual abilities do not usually } \\
\text { restrict independence in daily activities. }\end{array}$
\end{tabular}

LEVEL III Handles objects with difficulty; needs help to prepare and/or modify activities. The performance is slow and achieved with limited success regarding quality and quantity. Activities are performed independently if they have been set up or adapted.

\section{BFMF}

One hand manipulates without restrictions. The other hand manipulates without restrictions or has Limitations in more advanced fine motor skills.

(a) One hand manipulates without restrictions. The other hand has only ability to grasp or hold.

(b) Both hands have limitations in more advanced fine motor skills.

(a) One hand manipulates without restrictions. The other hand has no functional ability.

(b) One hand has limitations in more advanced fine motor skills. The other hand has only ability to grasp or worse.

LEVEL IV Handles a limited selection of easily managed objects in adapted situations. Performs part of activities with effort and limited success. Requires continuous support and assistance and/or adapted equipment for even partial achievement of the activity

LEVEL V Does not handle objects and has severely limited ability to perform even simple actions. Requires total assistance.

(a) Both hands have only ability to grasp.

(b) One hand has only ability to grasp. The other hand has only ability to hold or worse. The child needs support and/or adapted equipment.

Both hands have only ability to hold or worse. The child requires total assistance, even with adaptations.

Table 4. Description of the five level classifications of bimanual fine motor function (BFMF) [34] and manual ability classification system (MACS) [33]. 
$\mathrm{CP}$, but rather it aims to evaluate individual hand performance of the child carrying objects in his/her daily activities [33]. BFMF was defined by Beckung et al. in 2002. The system classifies grasping and manipulation skill in both hands by using a five-level system [34].

\section{Prevalent problems among children with $\mathrm{CP}$}

Brain damage among children with CP leads to impaired postural control, retarded balance and movement development and pattern. As a result of the consequential weakness, hypotonicity or hypertonicity, and abnormal inactivation of muscles requiring co-contraction are visible in these cases. Musculoskeletal problems accompany these neuromuscular problems. Seeing, hearing, speaking anomalies, and behavioral problems such as attention deficit and hyperkinesia and epilepsy and communication problems accompany the overall picture [35]. In the reports published by SCPE, it was communicated that there is epilepsy story of 1 out of each 3 child with CP [36].

\section{Health-related quality of life (HRQOL) in children with cerebral palsy}

*World Health Organization (WHO) provided this definition for quality of life (QOL); "the way an individual perceives his/her own state within the context of one's culture and value system." In the habitat of a person, the concept of QOL that includes one's personal goals, expectations, standards and interests; items such as physical health, mental health, level of independence, social relations, environmental factors and personal beliefs are based on subjectivity reference $[37,38]$.

WHO cites that QOL does not simply indicate being free of ailments but rather QOL accentuates physical, mental and social well-being of an individual. QOL is evident in four domains: personal inner domain (values, beliefs, aspirations, personal goals, coping with problems etc.), personal social domain (family structure, income level, employment status, social opportunities etc.), external natural environment domain (air, water quality etc.), and external social environmental domain (cultural, social and religious institutes, social opportunities, school, healthcare services, security, transportation, shopping etc.) [39].

QOL and general meaning of QOL require the requirements of clinical medicine and clinical studies to be distinguished, and for this reason, health-related quality of life (HRQOL) concept is mostly used in order to remove the uncertainties [40]. HRQOL refers to a patient's subjective perception on the contentment level of his/her own health status [41]. HRQOL is a study field that that focuses on the awareness of an individual on the fact that a person's physical, psychological and social welfare level and treatment for a disease render certain effects on his/ her daily life $[42,43]$. QOL and HRQOL are two concepts that are inextricably intertwined.

In relevant literature, the latest studies focused on the assessment of HRQOL in children with $\mathrm{CP}$ and directed at increasing the level of HRQOL are significantly critical [44]. Functional 
deficits that develop among children with $\mathrm{CP}$ due to the accompanying physical, cognitive, sensory, emotional, and social impairments block these children's capacity to perform their assigned-social roles, thereby leading to major collapses in the level of HRQOL [44, 45].

Depending on the severity of impact, children with CP are subject to different types of functional limitations and these functional limitations pose adverse effects on their HRQOL level. Further to that, even among children with analogue functional limitation, it is feasible to detect a different level of HRQOL impact [46].

\subsection{HRQOL measures for children with cerebral palsy}

Usage of both generic and condition-specific QOL scales is accepted as a standard for determining the changes in QOL. Generic scales focus on the wide perspective of QOL and health situation and are used in general population or in a wide scale consisting of various illnesses [40]. General evaluation scales evaluate the general state of well-being and achieve the subjective measurement of treatment results in case of various illnesses. Disease-specific scales evaluate a specific diagnosis group or a patient population. Many researchers think that disease-specific or condition-specific scales are more sensitive compared to general scales [47].

\subsubsection{Generic measures}

KINDL: KINDL is a generic HRQOL measure for children and adolescents with CP. It was initially developed in German [48]. There are different versions of the scale for different age groups. Among these, Kiddy-KINDL is used for children aged 4-7 and is a version applied through the interviewer (person providing care for child). Other versions are Kid-KINDL used for children aged 8-12 and Kiddo-KINDL used for adolescents aged 13-16. Adult forms of these versions are also available. The scale consists of 24 items and 6 dimensions (physical well-being, spiritual well-being, self-confidence, family, friends, daily activities at school). High scores show that the HRQOL is good [41, 49, 50].

KIDSCREEN: KIDSCREEN is a generic QOL instrument for aged 8-18 children and adolescent with CP. Instrument available in three versions; original long version, 27 -item version, and 10 item index version. Original long version consists of 52 items in 10 dimensions; physical well-being, psychological well-being, moods and emotions, self-perception, autonomy, parent relations and home life, social support and peers, school environment, social acceptance (bullying), financial resources. 27-item version evaluates QOL in five dimensions; physical well-being, psychological well-being, parent relations and autonomy, social support, and peers and school. Both instruments self-report and parent-report forms are available [51].

Child Health Questionnaire (CHQ): The Child Health Questionnaire (CHQ) is a generic QOL measure for children for children from 5-to-18 years of age. The scale consists of 14 physical and psychosocial domains: general health perceptions, physical functioning, role/social physical functioning, bodily pain, role/social emotional functioning, role/social behavioral functioning, parent impact-time, parent impact-emotional, self-esteem, mental health, behavior, family activities, family cohesion, and change in health. While CHQCF87 (the child-report questionnaire) consists of 87 items, the long parent-report questionnaire (CHQ-PF50) consists of 50 items, and the short parent-report questionnaire (CHQ-PF28) consists of 28 items [52, 53]. 
TACQOL: TACQOL is a general scale developed in order to evaluate the QOL of children aged 6-15 with chronic disease, about health. It has two versions named Parent-form (TACQOL-PF) and Child-form (TACQOL-CF). TACQOL-PF is used for children aged 6-15, and TACQOL-CF is used for children aged 8-15. Both scales have seven domains containing 56 items [54, 55].

Pictured Child's Quality of life self Questionnaire (AUQUEI): AUQUEI is a generic measure, evaluates the child's subjective QOL. Two versions are available as ages 3-5 and ages 6-11 and explore following domains; family and social relations, activity (play, schoolarity, leisure), health, functions (sleeping, alimentation), separation [56, 57].

Young Adult Quality of life (YAQOL): YAQOL is an instrument for young adults aged 18-25. The measure consists of five domains; physical health, psychological well-being, social relationship, role function, environmental context and takes approximately $25 \mathrm{~min}$. Answer options include four-point Likert scales ( 1 = not at all, 2 = somewhat, $3=$ usually, $4=$ definitely; 1 = false, $2=$ mostly false, $3=$ mostly true, $4=$ true; $1=$ never, $2=$ seldom, $3=$ sometimes, $4=$ often) $[58,59]$.

DISABKIDS Condition-Generic Module: The scale is a condition-generic module for aged 8-16 years children and adolescents diagnosed with different chronic conditions, and scale has two versions. The long version consists of 37 Likert-scaled items in three dimensions (DCGM-37): mental (independence: 6 items, emotion: 7 items), social (social inclusion: 6 items, social exclusion: 6 items), and physical (limitation: 6 items, treatment: 6 items), and the short version consists of 12 items [60].

Child Health and Illness Profile (CHIP): CHIP is a generic health status and HRQOL measure with 2 forms: CHIP-CE (Child Health and Illness Profile-Child Edition) and CHIP-AE (Child Health and Illness Profile-Adolescent Edition). CHIP-CE is a generic health status and HRQOL instrument for children 6-11 years old or their parents. CHIP-CE consists of four domains: satisfaction, comfort, resilience, and risk avoidance [61]. There is also a parent report form of CHIP-CE. The CHIP-AE is a self-administered (for 11-17 years old) generic health status and HRQOL instrument. CHIP-AE includes six domains (satisfaction, discomfort, resilience, risk avoidance, achievement, disorders), and 20 subdomains consist of 107 items plus an additional 46 (disease or injury specific) items [62, 63].

Exeter Health-Related Quality of Life Measure (EHRQOL): EHRQOL is a generic computerdelivered measure assesses self-reported HRQOL in 6-11 aged children. The scale includes seven domains (activity limitation, physical symptoms, negative feelings, self image, relation with friends, scholar functioning, interaction with family) and consists of 16 pictures, and it takes approximately $20 \mathrm{~min}[56,64]$.

Generic Children's Quality of Life Measure (GCQ): GCQ assesses perceived QOL in children aged between 6 and 14. Scale explores seven domains and consists of 50 questions $(25 \times 2)$; physical functioning, physical (sport), positive emotions, self-image, cognitive functioning, relation with friends, interaction with family. In the first section, the child choose the character in the story that he/she feels the most like (Perceived-Self), and in the second section, the child choose the character that he/she would most like to be (Preferred-Self). The measure has girl specific or boy specific version, the only differences being the color and gender of the characters $[56,65]$. 
'Vécu et Santé Perçue des Adolescents' (VSP-A): VSP-A is a generic self-administered measure for healthy and ill adolescents aged 11-17 [66].

Duke Health Profile-Adolescent Version (DHP-A): DHP-A is a 17-item generic self-report measure and consists of four dysfunction dimensions (anxiety, depression, pain, disability), and six health dimensions (physical, mental, social, general health, perceived health, selfesteem). It is used in adolescents ged between 13 to 18 [56, 67].

\subsubsection{Condition-specific measures}

PedsQOL Cerebral Palsy Module: PedsQOL Cerebral Palsy Module is a condition-specific HRQOL instrument for toddlers, young children, children and teens with $\mathrm{CP}$. The module has parent-report and self-report forms. Parent-report for toddler (ages 2-4) composed of 22 items comprising five dimensions, parent and child report for young children (ages 5-7), children (ages 8-12), teens (ages 13-17) composed of 35 items comprising seven dimensions. The seven dimensions include daily activities ( 9 items), school activities (4 items), movement and balance (5 items), pain and hurt (5 items), fatigue (5 items), eating activities (5 items), speech and communication (5 items) domains. There are no school activities and speech and communication dimensions in parent-report for toddler form. High scores indicate lower problems [68].

Caregiver Priorities and Child Health Index of Life with Disabilities (CPCHILD): This is a disease-specific instrument for children and adolescents aged 5-18 years with CP. CPCHILD consists of 36 items in six domains. These are personal care (8 items), positioning, transfer, and mobility (8 items), communication and social interaction (7 items), comfort, emotions, and behavior (9 items), health (3 items), and overall quality of life (1 item). The degree of difficulty of accomplishing activity was rated on a seven-point ordinal scale (0: no problem at all, 6: impossible). The level of assistance required was rated on a six-point ordinal scale from 0 ('Independent') to 5 ('Total assistance'). For Comfort, Emotions, and Behavior domain, the frequency of discomfort was rated on a six-point ordinal scale from 0 ('None of the time') to 5 ('All the time'). In the health and overall quality of life domain, items were rated on a six-point ordinal scale. Last, Section 7 (Importance of items) determines the caregivers' rating of the importance of each of the questionnaires' items toward their child's overall quality of life by using a six-point ordinal scale, from 0 ('Least important') to 5 ('Most important'). The questionnaire took approximately $20 \mathrm{~min}$ to complete [69].

DISABKIDS CP disease module: DISABKIDS CP disease module is a condition-specific instrument for children and adolescents aged 8-18 years with $\mathrm{CP}$, consists of 14 disease-specific questions and 2 further items on communication about the condition. High scores remark better quality of life [70, 71].

Cerebral Palsy Quality of Life Questionnaire for Children (CPQOL-Child): CPQOL has two forms: primary caregiver-proxy report for children aged 4-12 years and self-report form for children aged 9-12 years. Primary caregiver-proxy report includes seven domains (social well-being and acceptance, functioning, participation and physical health, emotional wellbeing, access to services, pain and impact of disability, and family health) and consists of 66 
items. Self-report form includes 5 domains and 52 items, except for pain and impact of disability, and family health domain [72].

Lifestyle Assessment Questionnaire-Cerebral Palsy: Lifestyle Assessment Questionnaire Cerebral Palsy includes 46 items in six dimensions: physical independence, mobility, clinical burden, schooling, economic burden, and social integration. Total score of scale (Lifestyle Assessment Score-LAS) expressed in percent. The classification of the HRQOL with regard to LAS: good (<30\%); mildly affected (30-50\%); moderately affected (51-70\%); and severely affected $(>70 \%)[73,74]$.

Functional limitations, self-care difficulties, behavioral problems, seizures, cognitive, sensory, social and emotional impairments and difficulties of daily life activities can affect healthrelated quality of life in children and adolescents with cerebral palsy. So, it is important to evaluate health-related quality of life in cerebral palsy. It is stated that there are many generic instruments to evaluate health-related quality of life. However, using specific instruments for cerebral palsy is more sensitive than generic instruments to evaluate effect of cerebral palsy in children's health-related quality of life.

\title{
Acknowledgements
}

We would like to thank our patients for the permission to use their photographs.

\section{Author details}

\author{
Ozlem Cinar Ozdemir ${ }^{1 *}$ and Sezen Tezcan ${ }^{2}$
}

*Address all correspondence to: ozlemcinar314@hotmail.com

1 Abant Izzet Baysal University, School of Physical Therapy and Rehabilitation, Bolu, Turkey 2 Pediatric Rehabilitation Center, Bolu, Turkey

\section{References}

[1] Krägeloh-Mann I, Cans C. Cerebral palsy update. Brain and Development. 2009;31(7):53744. do1:10.1016/j.braindev.2009.03.009

[2] Johnson A. Prevalence and characteristics of children with cerebral palsy in Europe. Developmental Medicine \& Child Neurology. 2002;44(09):633-40. do1:10.1017/S00121622 01002675

[3] Yeargin-Allsopp M, Braun KVN, Doernberg NS, Benedict RE, Kirby RS, Durkin MS. Prevalence of cerebral palsy in 8-year-old children in three areas of the United States in 2002: a multisite collaboration. Pediatrics. 2008;121(3):547-54. do1:10.1542/peds.2007-1270 
[4] Oskoui M, Coutinho F, Dykeman J, Jetté N, Pringsheim T. An update on the prevalence of cerebral palsy: a systematic review and meta-analysis. Developmental Medicine \& Child Neurology. 2013;55(6):509-19. do1:10.111/dmcn.12080

[5] Tsui K, Yiu B, Cheng C, Chan C. Prevalence study of cerebral palsy in Hong Kong children. Hong Kong Medical Journal. 2006;12(3):180-4.

[6] Liu J-M, Li S, Lin Q, Li Z. Prevalence of cerebral palsy in China. International Journal of Epidemiology. 1999;28(5):949-54. do1:10.1093/ije/28.5.949

[7] Serdaroglu A, Cansu A, Ozkan S, Tezcan S. Prevalence of cerebral palsy in Turkish children between the ages of 2 and 16 years. Developmental Medicine \& Child Neurology. 2006;48(6):413. do1:10.1017/S0012162206000910

[8] Banerjee TK, Hazra A, Biswas A, Ray J, Roy T, Raut DK, et al. Neurological disorders in children and adolescents. The Indian Journal of Pediatrics. 2009;76(2):139-46. do1:10.1007/ s12098-008-0226-Z

[9] Panteliadis CP. Epidemiology of cerebral palsy. In: Cans C, Sellier E, Mermet M-A, editors. Cerebral Palsy. Germany; 2011. pp. 17-27.

[10] Prevalence of Cerebral Palsy 2016 [cited 03.12.2016]. Available from: http://www.cerebralpalsy.org/about-cerebral-palsy/prevalence-and-incidence.

[11] Reddihough DS, Collins KJ. The epidemiology and causes of cerebral palsy. Australian Journal of Physiotherapy. 2003;49(1):7-12. do1:10.1016/S0004-9514(14)60183-5

[12] MacLennan AH, Thompson SC, Gecz J. Cerebral palsy: causes, pathways, and the role of genetic variants. American Journal of Obstetrics and Gynecology. 2015;213(6):779-88. do1:10.1016/j.ajog.2015.05.034

[13] McIntyre S, Taitz D, Keogh J, Goldsmith S, Badawi N, Blair E. A systematic review of risk factors for cerebral palsy in children born at term in developed countries. Developmental Medicine \& Child Neurology. 2013;55(6):499-508. do1:10.1111/dmcn.12017

[14] Platt MJ, Cans C, Johnson A, Surman G, Topp M, Torrioli MG, et al. Trends in cerebral palsy among infants of very low birthweight $(<1500 \mathrm{~g})$ or born prematurely $(<32$ weeks) in 16 European centres: a database study. The Lancet. 2007;369(9555):43-50. do1:10.1016/ S0140-6736(07)60030-0

[15] Gladstone M. A review of the incidence and prevalence, types and aetiology of childhood cerebral palsy in resource-poor settings. Annals of Tropical Paediatrics. 2010;30(3):18196. do1:10.1179/146532810X12786388978481

[16] Dodd KJ, Imms C, Taylor NF. What is cerebral palsy? In: Imms C, Dodd KJ, editors. Physiotherapy and Occupational Therapy for People with Cerebral Palsy. 1st ed. London: British Library Cataloguing; 2010. pp. 7-31. 
[17] Rosenbaum P, Paneth N, Leviton A, Goldstein M, Bax M, Damiano D, et al. A report: the definition and classification of cerebral palsy. Developmental Medicine \& Child Neurology Supplement 2007;109(suppl 109):8-14. do1:10.1111/j.1469-8749.2007.tb12610.x

[18] Takahashi R, Yamada M, Takahashi T, Ito T, Nakae S, Kobayashi Y, et al. Risk factors for cerebral palsy in preterm infants. Early Human Development. 2005;81(6):545-53. do1:10.1016/j.earlhumdev.2004.11.007

[19] Bax M, Goldstein M, Rosenbaum P, Leviton A, Paneth N, Dan B, et al. Proposed definition and classification of cerebral palsy. Developmental Medicine \& Child Neurology. 2005;47(08):571-6. do1:10.1017/S001216220500112X

[20] Baxter P, Morris C, Rosenbaum P, Paneth N, Leviton A, Goldstein M, et al. The definition and classification of cerebral palsy. Developmental Medicine \& Child Neurology. 2007;49(s109):1-44. do1:10.1111/j.1469-8749.2007.00001.x

[21] Tarsuslu T, Livanelioğlu A. The effect of pain on activity independence and healthrelated quality of life in cerebral palsied individuals. Fizyoterapi ve Rehabilitasyon Dergisi. 2008;19:117-22. do1:10.5505/agri.2011.93695

[22] O'Shea M. Cerebral palsy. Seminars in Perinatology. 2008;32:35-41.

[23] Ferrari A, Cioni G. Tetraplegic forms. In: Ferrari A, Lodesani M, Muzzini S, Pascale R, Sassi S, editors. The Spastic Forms of Cerebral Palsy. Italy 2010. pp. 241-73.

[24] Sankar C, Mundkur N. Cerebral palsy-definition, classification, etiology and early diagnosis. The Indian Journal of Pediatrics. 2005;72(10):865-8. do1:10.1007/BF02731117

[25] Mewasingh LD, Demil A, Christiaens FJ, Missa A-M, Cheron G, Dan B. Motor strategies in standing up in leukomalacic spastic diplegia. Brain and Development. 2002;24(5):291-5. do1:http://dx.doi.org/10.1016/S0387-7604(02)00059-1

[26] Panteliadis CP. Clinical characteristics. In: Papavasiliou A, Panteliadis CP, editors. Cerebral Palsy. Germany: Dustri-Verlag; 2011. pp. 89-105.

[27] Hou M, Zhao J-H, Yu R. Recent advances in dyskinetic cerebral palsy. World Journal of Pediatrics. 2006;1:23-8.

[28] Tecklin JS. Pediatric Physical Therapy. 3rd ed. United States of America: Lippincott Williams \& Wilkins; 1999.

[29] Krigger KW. Cerebral palsy: an overview. American Family Physician. 2006;73(1):91-100.

[30] Jan JE, Lyons CJ, Heaven RK, Matsuba C. Visual impairment due to a dyskinetic eye movement disorder in children with dyskinetic cerebral palsy. Developmental Medicine \& Child Neurology. 2001;43(02):108-12. do1:10.1111/j.1469-8749.2001.tb00725.x

[31] Beckung E, Hagberg G, Uldall P, Cans C. Probability of walking in children with cerebral palsy in Europe. Pediatrics. 2008;121(1):e187-e92. do1:10.1542/peds.2007-0068 
[32] Palisano R, Rosenbaum P, Walter S, Russell D, Wood E, Galuppi B. Development and reliability of a system to classify gross motor function in children with cerebral palsy. Developmental Medicine \& Child Neurology. 1997;39(4):214-23. do1:10.1111/j.14 69-8749.1997.tb07414.x

[33] Eliasson A-C, Krumlinde-Sundholm L, Rösblad B, Beckung E, Arner M, Öhrvall A-M, et al. The Manual Ability Classification System (MACS) for children with cerebral palsy: scale development and evidence of validity and reliability. Developmental Medicine \& Child Neurology. 2006;48(07):549-54. do1:10.1017/S0012162206001162

[34] Beckung E, Hagberg G. Neuroimpairments, activity limitations, and participation restrictions in children with cerebral palsy. Developmental Medicine \& Child Neurology. 2002;44(5):309-16. do1:10.1111/j.1469-8749.2002.tb00816.x

[35] Levit S. Treatment of Cerebral Palsy and Motor Delay. 5th ed. Chichester: WileyBlackwell Publication; 2010.

[36] Sellier E, Uldall P, Calado E, Sigurdardottir S, Torrioli MG, Platt MJ, et al. Epilepsy and cerebral palsy: characteristics and trends in children born in 1976-1998. European Journal of Paediatric Neurology. 2012;16(1):48-55. do1:10.1016/j.ejpn.2011.10.003

[37] Organization WH. WHOQOL: Measuring Quality of Life. Switzerland: World Health Organization; 1997.

[38] Kaya M. Ankara“ da 112 Acil Yardım Hizmetlerinde Çalısan Sağlık Personelinin Öznel Yasam Kalitelerinin Değerlendirilmesi [thesis]. Ankara: Ankara Üniversitesi; 2003.

[39] Basaran S, Güzel R, Sarpel T. Qualıty of life and health outcome assessment questionnaires. Romatizma. 2005;20(1):55-63.

[40] Fayers P, Machin D. Quality of Life. 2nd ed. Chichester: John Wiley \& Sons Ltd.; 2007.

[41] Eser E, Yüksel H, Baydur H, Erhart M, Saatli G, Özyurt BC, et al. The Psychometric Properties of the New Turkish Generic Health-Related Quality of Life Questionnaire for Children (Kid-KINDL). Türk Psikiyatri Dergisi. 2008;19(4):409-17.

[42] Erdoğanoğlu Y, Günel MK. Investigation of health-related quality of life of families with have children with cerebral palsy. Toplum Hekimliği Bülteni. 2007;26(2):35-9.

[43] Erdoğanoğlu Y. Serebral Paralizili Çocuklar ve Ailelerinde Sağlıkla İlgili Yasam Kalitesinin Değerlendirilmesi [thesis]. Ankara: Hacettepe Üniversitesi; 2006.

[44] Bjornson K, McLaughlin J. The measurement of health-related quality of life (HRQL) in children with cerebral palsy. European Journal of Neurology. 2001;8(s5):183-93. do1:10.1046/j.1468-1331.2001.00051.x

[45] Schneider JW, Gurucharri LM, Gutierrez AL, Gaebler-Spira DJ. Health-related quality of life and functional outcome measures for children with cerebral palsy. Developmental Medicine \& Child Neurology. 2001;43(09):601-8. do1:10.1111/j.1469-8749.2001.tb00242.x 
[46] Liptak GS, O'Donnell M, Conaway M, Chumlea WC, Worley G, Henderson RC, et al. Health status of children with moderate to severe cerebral palsy. Developmental Medicine \& Child Neurology. 2001;43(6):364-70. do1:10.1111/j.1469-8749.2001.tb00223

[47] Wiebe S, Guyatt G, Weaver B, Matijevic S, Sidwell C. Comparative responsiveness of generic and specific quality-of-life instruments. Journal of Clinical Epidemiology. 2003;56(1):52-60.

[48] Questionnaires 1998. Available from: http://www.kindl.org/english/questionnaires/.

[49] Ravens-Sieberer U, Bullinger M. Assessing health-related quality of life in chronically ill children with the German KINDL: first psychometric and content analytical results. Quality of Life Research. 1998;7(5):399-407. do1:10.1023/A:1008853819715

[50] Ravens-Sieberer U, Bullinger M. News from the KINDL-questionnaire: a new version for adolescents. Quality of Life Research. 1998: 653-653.

[51] Ravens-Sieberer U, Herdman M, Devine J, Otto C, Bullinger M, Rose M, et al. The European KIDSCREEN approach to measure quality of life and well-being in children: development, current application, and future advances. Quality of Life Research. 2014;23(3):791-803. do1:10.1007/s11136-013-0428-3

[52] Hullmann SE, Ryan JL, Ramsey RR, Chaney JM, Mullins LL. Measures of general pediatric quality of life: Child Health Questionnaire (CHQ), DISABKIDS Chronic Generic Measure (DCGM), KINDL-R, Pediatric Quality of Life Inventory (PedsQL) 4.0 Generic Core Scales, and Quality of My Life Questionnaire (QoML). Arthritis Care \& Research. 2011;63(S11):S420-S30. do1:10.1002/acr.20637

[53] CHQ: Child Health Questionnaire ${ }^{\mathrm{TM}}$ 2016. Available from: https://www.healthactchq. com/survey/chq.

[54] Verrips EG, Vogels TG, Koopman HM, Theunissen NC, Kamphuis RP, Fekkes M, et al. Measuring health-related quality of life in a child population. The European Journal of Public Health. 1999;9(3):188-93.

[55] Vogels T, Verrips G, Koopman H, Theunissen N, Fekkes M, Kamphuis R. TACQOL Manual: Parent Form and Child Form. Leiden: Leiden Center for Child Health and Pediatrics LUMC-TNO; 2000.

[56] Viehweger E, Robitail S, Rohon M-A, Jacquemier M, Jouve J-L, Bollini G, et al., editors. Measuring quality of life in cerebral palsy children. Annales de Réadaptation et de Médecine Physique; 2008: Elsevier. do1:10.1016/j.annrmp.2007.12.007

[57] Pictured Child's Quality of Life Self Questionnaire (AUQUEI) 2016. Available from: https://eprovide.mapi-trust.org/instruments/pictured-child-s-quality-of-life-self-questionnaire \#basic_description.

[58] Jiang B, Walstab J, Reid SM, Davis E, Reddihough D. Quality of life in young adults with cerebral palsy. Disability and Health Journal. 2016. do1:10.1016/j.dhjo.2016.04.006 
[59] Chen H, Cohen P, Kasen S, Gordan K, Dufur R, Smailes E. Construction and validation of a quality of life instrument for young adults. Quality of Life Research. 2004;13(4):74759. do1:10.1023/B:QURE.0000021700.42478.ab

[60] Schmidt S, Debensason D, Mühlan H, Petersen C, Power M, Simeoni MC, et al. The DISABKIDS generic quality of life instrument showed cross-cultural validity. Journal of Clinical Epidemiology. 2006;59(6):587-98. do1:10.1016/j.jclinepi.2005.09.012.

[61] Riley AW, Forrest CB, Rebok GW, Starfield B, Green BF, Robertson JA, et al. The child report form of the CHIP-Child Edition: reliability and validity. Medical Care. 2004;42(3):221-31.

[62] Riley, Anne W., et al. "Reliability and validity of the adolescent health profile-types." Medical care 1998; 36(8): 1237-1248.

[63] Starfield B, Riley AW, Green BF, Ensminger ME, Ryan SA, Kelleher K, et al. The adolescent child health and illness profile: a population-based measure of health. Medical Care. 1995; 33(5): 553-566.

[64] Eiser C, Cotter I, Oades P, Seamark D, Smith R. Health-related quality-of-life measures for children. International Journal of Cancer. 1999;83(S12):87-90. do1:10.1002/ (SICI)1097-0215(1999)83:12+<87::AID-IJC16>3.0.CO;2-O

[65] Collier J, MacKinlay D, Phillips D. Norm values for the Generic Children's Quality of Life Measure (GCQ) from a large school-based sample. Quality of Life Research. 2000;9(6):617-23. do1:10.1023/A:1008915700210

[66] Simeoni M, Auquier P, Antoniotti S, Sapin C, San Marco J. Validation of a French healthrelated quality of life instrument for adolescents: the VSP-A. Quality of Life Research. 2000;9(4):393-403. do1:10.1023/A:1008957104322

[67] Vo TXH, Guillemin F, Deschamps J-P. Psychometric properties of the DUKE Health Profile-adolescent version (DHP-A): a generic instrument for adolescents. Quality of Life Research. 2005;14(10):2229-34. do1:10.1007/s11136-005-7021-3

[68] Varni JW, Burwinkle TM, Berrin SJ, Sherman SA, BA KA, Malcarne VL, et al. The PedsQL in pediatric cerebral palsy: reliability, validity, and sensitivity of the Generic Core Scales and Cerebral Palsy Module. Developmental Medicine \& Child Neurology. 2006;48(6):442-9. do1:10.1111/j.1469-8749.2006.tb01293.x

[69] Narayanan UG, Fehlings D, Weir S, Knights S, Kiran S, Campbell K. Initial development and validation of the Caregiver Priorities and Child Health Index of Life with Disabilities (CPCHILD). Developmental Medicine \& Child Neurology. 2006;48(10):80412. do1:10.1111/j.1469-8749.2006.tb01227.x

[70] Baars RM, Atherton CI, Koopman HM, Bullinger M, Power M. The European DISABKIDS project: development of seven condition-specific modules to measure health related quality of life in children and adolescents. Health and Quality of Life Outcomes. 2005;3(1):1. do1:10.1186/1477-7525-3-70 
[71] Content of the DISABKIDS Cerebral Palsy Module. 2012. Available from: http://www. disabkids.org/questionnaire/disabkids-disease-modules/cerebral-palsy-module/.

[72] Waters E, Davis E, Mackinnon A, Boyd R, Graham HK, Kai Lo S, et al. Psychometric properties of the quality of life questionnaire for children with CP. Developmental Medicine \& Child Neurology. 2007;49(1):49-55. do1:10.1017/S0012162207000126.x

[73] Dobhal M, Juneja M, Jain R, Sairam S, Thiagarajan D. Health-related quality of life in children with cerebral palsy and their families. Indian Pediatrics. 2014;51(5):385-7. dor:10.1007/s13312-014-0414-z

[74] Mackie P, Jessen E, Jarvis S. The lifestyle assessment questionnaire: an instrument to measure the impact of disability on the lives of children with cerebral palsy and their families. Child: Care, Health and Development. 1998;24(6):473-86. do1:10.1046/j. 1365-2214.1998.00083.x 
